\title{
The ecological point of view could complicate the attempt to create a halophytes database? The Romanian story
}

\author{
Grigore Marius-Nicuşor \\ Faculty of Biology, Alexandru Ioan Cuza University, Iasi, Romania \\ Carol I, 20 A, 700505 \\ e-mail: mariusgrigorepsyche@yahoo.com
}

\begin{abstract}
Summary. In this paper we discuss some inherent difficulties occurring when we tried to realize a Romanian halophytes database. We are focusing here especially on the way in which the ecological approach of halophytes could facilitate or complicate this attempt. Our previous experience, as well the prospective improvements in this regard are considered.
\end{abstract}

Key words: database, saline habitats, salt tolerant plants, ecological definitions.

\section{Introduction}

Dealing with any aspect of a certain ecological group of plants could be a challenging business, due to the complexity of definitions, adaptive features and subtle ecological interrelations between plants and their environments. Halophytes represent no doubt a very heterogeneous group of plants; they are widely distributed in many families, as well occurring in various saline habitats.

However, despite the great progress recorded in halophytes biology, their definition remains sometimes ambiguous. Anyway, the most largely accepted and used definition is based on the ability of halophytes to complete the life cycle in a alt concentration of at least $200 \mathrm{mM} \mathrm{NaCl}$ under conditions similar to those that might be encountered in the natural environment (Flowers et al. 1986). Halophytes are therefore plants that tolerate salt concentrations that kill 99\% of other species (Flowers \& Colmer 2008).

There are many definitions of halophytes; some of these were recently summarized and discussed by us (Grigore et al. 2010), when we tried to pay attention on the huge diversity of the origin and nature of halophytes definitions. We were able to conclude that existed definitions are based on ecological, physiological and biochemical criteria and sometimes here are consistent variations or combinations of these criteria.

\section{Learning from the previous attempt to create a Romanian halophytes database}

In 2008, we published a list with Romanian salt tolerant plants (Grigore 2008a), or plants susceptible to be salt tolerant. This compilation, derived mainly from data extracted from Romanian literature, shown us that the number of salt plants depends, inevitably, on definitions and characterizations attributed to halophytes by various authors. But in Romania, the experience and background in working with halophytes are quite limited, at least in the terms of physiological and experimental approach. This was accompanied by some kind of rich floristic and ecological work, but this vision was supported by an intuitive and ecological definition of halophytes, strictly related to saline environments. At this point of discussion, we faced with two derived difficulties, when we chose the criteria used for including species in this database. First, the ecological definitions are versatile and subjected, in some extent, 
to arbitrariness. Second, this type of definitions had to be correlated with the habitats where these species vegetate and where they have been observed and collected. Here, again a problem. Although the Romanian language associated with hipersaline environments is scarce comparatively with others, the botanists used a non technical term (Grigore 2008b) when referring on this general type of ecosystem (sărătură). In addition, even when more precise terms were adopted from soil science (saline and alkali soils) to be used by botanists, they actually assimilated them to the older, non technical term. In this way, a "tradition" in relation with definitions of halophytes and saline environments was created and preserved over the time. In addition, a real semantic field concentrating the words describing the halophytes occurred and it is still used, both in Romanian, as well in English (Tab. 1).

So, we selected from Romanian literature those species designated by different authors as halophytes lato sensu (see also Tab. 1) and/or those species found in saline environments. When a botanist said that a certain species vegetates in a saline habitat, we had to rely, a priori, on this affirmation.

Summarizing, the difficulties which we had to face on were the following:

a) the lack of a precise (and idealistically a single) definition of halophytes;

b) problems with the definition and features of saline environments;

c) possible misidentifications of all species growing in a certain habitat;

d) special nomenclatural situations due to some periods in Romanian history (the actual geographical surface or Romania suffered changes during the time);

subjectivity of some Romanian botanists when offering

e) some ecological notes; many of them comprise approximations regarding the traits of a given ecosystem. For instance, we found that many species are cited in a habitat which is described as more or less, moderately, intensely, sometimes - salinized.

Following these criteria but taking into considerations all the risks derived from above mentioned difficulties, we found a number of approximately 756 salt tolerant plants growing in salinized habitats in Romania. However, it is expected that the real number of halophytes to be much lower than this number suggests. In fact, we think that here it's just a problem of interpretation of some basic concepts (halophyte, saline environments); if they are fragile, as criteria, the number, as result, will be uncertain, consequently.
Table 1. Semantic field with different words related to halophytes (after Grigore et al. 2010)

\begin{tabular}{|l|l|}
\hline \multicolumn{1}{|c|}{ Romanian } & \multicolumn{1}{c|}{ English } \\
\hline $\begin{array}{l}\text { Halofite; plante } \\
\text { de sărătură; plante } \\
\text { halofile; plante } \\
\text { iubitoare de săruri; } \\
\text { plante de locuri sărate. }\end{array}$ & $\begin{array}{l}\text { Halophytes; salt tolerant plants; salt } \\
\text { plants; high salinity tolerant plants; } \\
\text { salt loving plants; halophylous } \\
\text { plants; halophytic plants; maritime } \\
\text { plants }\end{array}$ \\
\hline
\end{tabular}

\section{A new Romanian halophytes database}

Currently, we are working on a new, revised and extended version of a previous one of this database. In addition, we will include some extensive data regarding the biology of halophytes: life form, plant type, ecological characterization, economical value photosynthetic type and salinity threshold (when possible).

\section{Aknowledgements}

This paper was supported by the POSDRU/89/1.5/S/49944 project "Developing the innovation capacity and improving the impact of research through post-doctoral programmes”.

\section{References}

Flowers T. J. \& Colmer T. D., 2008, Salinity tolerance in halophytes, New Phytol. 179: 945-963.

Flowers T. J., Hajibagheri M. A. \& Clipson N. J. W., 1986, Halophytes, Quarterly Rev. Biol. 61: 313-337.

Grigore M.-N., 2008a, Halophytotaxonomy, List of Romanian salt tolerant plants, PIM Press, Iasi.

Grigore M.-N., 2008b, Introductory Halophytology, Integrative anatomy aspects, PIM Press, Iasi.

Grigore M.-N., Toma C. \& Boşcaiu M., 2010, Dealing with halopytes: an old problem, the same continuous exciting challenge, An. Şt. Univ. „Al. I. Cuza”, s. II.a. Biol. Veget. 56 (1): 21-32. 